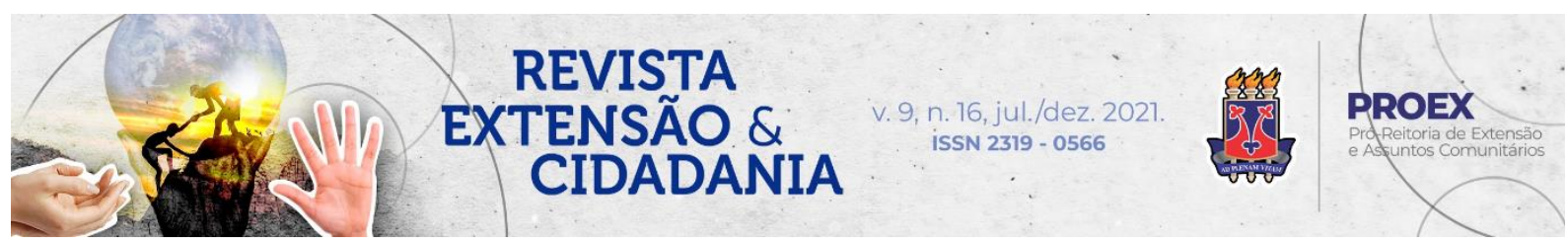

DOI: $10.22481 /$ recuesb.v9i16.8715

\title{
A LITERATURA NO ENSINO DE INGLÊS COMO LÍNGUA ESTRANGEIRA: DIÁLOGOS NO COMMUNICATION CAFÉ
}

\section{LITERATURE IN THE TEACHING OF ENGLISH AS A FOREIGN LANGUAGE: DIALOGUES HELD AT COMMUNICATION CAFÉ}

\section{LITERATURA EN LA ENSEÑANZA DEL INGLÉS COMO LENGUA EXTRANJERA: DIÁLOGOS EN COMUNICACIÓN CAFÉ}

Ana Ketilly Manhães Magalhães ${ }^{1}$

Alice Vasconcelos Silva ${ }^{2}$

Clarissa Costa e Silva ${ }^{3}$

Fernando Gonçalves de Souza Neto ${ }^{4}$

Mateus Freire Santana Silva ${ }^{5}$

Resumo: Este estudo discute o papel da literatura no ensino de inglês como língua estrangeira, em especial, no tocante a como esta pode auxiliar estudantes em seus processos de aprendizagem. Este trabalho surge como resultado de reflexões tecidas nas disciplinas de Literatura Inglesa e Norte-Americana e no projeto de extensão Communication Café, da Universidade Estadual do Sudoeste da Bahia, Campus Vitória da Conquista. Neste estudo, a partir das experiências (de leitura, produção e/ou reflexões de textos literários) vivenciadas nestes dois contextos, traçamos um paralelo entre a importância da literatura e as formas de a incorporarmos ao processo de ensino e aprendizagem da língua inglesa. Pensar o lugar da literatura no ensino de inglês como língua estrangeira abre portas para um possível diálogo

\footnotetext{
${ }^{1}$ Discente do curso de graduação em Letras Modernas, da Universidade Estadual do Sudoeste da Bahia (UESB), Vitória da Conquista, Bahia, Brasil. O rcid: https://orcid.org/0000-0003-2512-9639 E-mail: 201710703@uesb.edu.br

2 Discente do curso de graduação em Letras Modernas, da Universidade Estadual do Sudoeste da Bahia (UESB), Vitória da Conquista, Bahia, Brasil. Orcid: https://orcid.org/0000-0002-3679-8961 E-mail: 201710354@uesb.edu.br

${ }^{3}$ Mestre em Linguística Aplicada. Professora Assistente de Língua Inglesa, da Universidade Estadual do Sudoeste da Bahia (UESB), Vitória da Conquista, Bahia, Brasil. Orcid: https://orcid.org/0000-0001-5118-9198 E-mail: clarissa.costa@uesb.edu.br

${ }^{4}$ Discente do curso de graduação em Letras Modernas, da Universidade Estadual do Sudoeste da Bahia (UESB), Vitória da Conquista, Bahia, Brasil. Orcid: https://orcid.org/0000-0001-6033-3104 E-mail: 201710590@uesb.edu.br

${ }^{5}$ Discente do curso de graduação em Letras Modernas, da Universidade Estadual do Sudoeste da Bahia (UESB), Vitória da Conquista, Bahia, Brasil. Orcid: https://orcid.org/0000-0003-0826-7538 E-mail: 201710364@uesb.edu.br
} 
interdisciplinar. Ainda, permite-nos uma leitura crítica de nossa trajetória humana, considerando a intrínseca relação entre literatura e sociedade (GOMES, 2009). A análise que apresentamos é fundamentada em uma perspectiva qualitativa de pesquisa, na qual a compreensão subjetiva e crítica dos autores (professora coordenadora do projeto e discentes do curso de Letras Modernas) ocupa lugar central (CONNELLY; CLANDININ, 2000). Este estudo poderá interessar a estudantes, professores e admiradores das várias facetas da língua inglesa.

Palavras-chaves: Literatura. Communication Café. aprendizagem. Interdisciplinaridade.

Abstract: This study discusses the role of literature in the teaching of English as a foreign language, especially, in terms of how it can help students in their learning process. This work comes as a result of reflections woven from English and North-American Literature classes and conversations held at Communication Café extension project, from Universidade Estadual do Sudoeste da Bahia, Vitoria da Conquista Campus. In this study, based on the experiences (of reading and discussing literary texts) shared in both contexts - in the classes and in the project - we establish a parallel between the importance of literature and the ways to including it into the teaching of English as a foreign language. Thinking about the place of literature in the teaching of English as a foreign language opens doors to an interdisciplinary dialogue. Yet, it allows us a critical reading of our paths as humans, considering the intrinsic relationship between literature and society (GOMES, 2009). The analysis presented through this study is supported by a qualitative research perspective, in which the authors' subjectivity and critical understanding take a central place (CONNELLY; CLANDININ, 2000). This study may interest students, teachers and admirers of the various layers of the English language.

Keywords: Literature. Communication Café. learning. Interdisciplinary.

Resumen: Este estudio analiza el papel de la literatura en la enseñanza del inglés como lengua extranjera, especialmente en cuanto a cómo puede ayudar a los estudiantes en sus procesos de aprendizaje. Este trabajo surge como resultado de reflexiones tejidas en las disciplinas de la literatura inglesa y norteamericana y en el proyecto de extensión Communication Café, en la Universidad Estatal del Sudoeste de Bahía, Campus Vitória da Conquista. En este estudio, a partir de experiencias (leer, producir y / o reflexionar sobre textos literarios) vividas en estos dos contextos, trazamos un paralelo entre la importancia de la literatura y las formas de incorporarla al proceso de enseñanza y aprendizaje de la lengua inglesa. Pensar en el lugar de la literatura en la enseñanza del inglés como lengua extranjera abre las puertas a un posible diálogo interdisciplinario. Aun así, nos permite una lectura crítica de nuestra trayectoria humana, considerando la relación intrínseca entre literatura y sociedad (GOMES, 2009). El análisis que presentamos se basa en una perspectiva de investigación cualitativa, en la que la comprensión subjetiva y crítica de los autores (profesor coordinador del proyecto y estudiantes del curso de Letras Modernas) ocupa un lugar central (CONNELLY; CLANDININ, 2000). Este estudio puede interesar a estudiantes, profesores y admiradores de las diversas facetas del idioma inglés. Faltan resultados y conclusiones.

Palabras clave: Literatura. Café de la comunicación. Aprendizaje. Interdisciplinariedad.

Revista Extensão \& Cidadania, v. 9, n. 16, p. 65-80, jul./dez. 2021.

ISSN 2319-0566 DOI: 10.22481/recuesb.v9i16.8715 


\section{Introdução}

Este trabalho busca discutir o papel da literatura no ensino de inglês como língua estrangeira e as possibilidades que esta junção oferece, com base em reflexões tecidas durante as disciplinas de Literatura Inglesa, Norte-Americana e nos encontros do Projeto de Extensão Communication Café, da Universidade Estadual do Sudoeste da Bahia (UESB). Por meio da experiência de leitura e discussão de textos literários, percebemos a riqueza e a importância destes como recursos valiosos a serem incorporados ao processo de ensino e aprendizagem de inglês, a partir desta percepção, nos indagamos sobre duas questões, as quais abordamos neste estudo: 1. Qual a importância da literatura na aprendizagem de inglês? 2. Quais são algumas formas de a integrarmos ao ensino de inglês?

A partir das reflexões da professora das disciplinas de Literatura Inglesa e NorteAmericana, coordenadora do Projeto de Extensão Communication Café, e dos discentes do curso de Letras Modernas, os quais cursaram essas disciplinas e participaram dos encontros do projeto, desenhamos uma análise crítica a fim de dar voz as nossas experiências e as percepções sobre essas questões levantadas. Este trabalho se justifica, dentre outras razões, pela possibilidade de explorarmos esse possível diálogo entre literatura e aprendizagem de inglês. Além disso, por propor que futuros professores e professores de inglês (re)pensem o lugar e papel que a literatura pode ocupar em suas salas de aula, afinal, será que criamos espaços para a literatura da língua alvo em nossas aulas? E, caso não façamos isso, como podemos iniciar? Essas são questões relevantes para o campo de estudos linguísticos e literários, bem como para a área de ensino e aprendizagem de inglês como língua estrangeira, uma vez que propõem que avaliemos nossas escolhas e práticas docentes, a fim de buscarmos potencializar as oportunidades de aprendizagem de nossos alunos.

Segundo Freire (1996), as escolhas que fazemos, enquanto educadores, devem se traduzir em atitudes responsáveis, conscientes, críticas e otimistas. Portanto, os conteúdos abordados em classe não deverão ser neutros ou distantes da realidade dos alunos, pelo contrário, estes conteúdos deverão dizer sobre esse aluno, informá-lo sobre a sociedade e formálo para atuar ativamente nesta. Apenas por meio desta dinâmica, segundo Freire (1996), contribuiremos para uma formação cidadã, em que um indivíduo integra a sociedade e a modifica, caso considere necessário. Esta maneira de pensarmos o processo de ensino, muitas vezes classificada como política, libertadora ou inovadora nada mais é do que um clamor para

Revista Extensão \& Cidadania, v. 9, n. 16, p. 65-80, jul./dez. 2021. 
que confiramos a devida atenção a cada elemento ao nosso redor, e possamos utilizá-los como ferramentas valiosas no processo de ensino e aprendizagem.

Esse exercício de pensarmos sobre nossa realidade e sobre suas potencialidades para o processo de ensino traz à tona a necessidade de olharmos para a nossa história, o que sabemos e o que temos disponível sobre esta. Um dos canais, pelo qual podemos acessar esse conhecimento e buscarmos compreender mais sobre nossa história, é o dos textos literários, que se referem a todos os gêneros textuais (de ficção ou não) produzidos pela literatura, no caso deste estudo, a Literatura Inglesa e Norte-Americana. A partir destes textos, podemos ter acesso as histórias de um determinado lugar ou contexto, de um determinado indivíduo ou grupo de indivíduos, dos sentimentos, emoções, condições econômicas, políticas, sociais, culturais, psíquicas, que delineiam uma situação ou um momento ou período histórico. Os textos literários, conforme discute Hişmanoğlu (2005), oferecem um mar de histórias que podemos conhecer, explorar e compor sentidos a partir do que sabemos e podemos aprender.

Neste estudo, o contato que tivemos com os textos que compõem a Literatura Inglesa e Norte-Americana nos ofereceu uma série de histórias e possibilidades. No Projeto de Extensão Communication Café, este contato ocorreu pela troca de informações entre os participantes, em que cada um sugeria uma referência de leitura, compartilhava um texto/livro ou discutia sobre os sentidos de algo lido nos encontros (poemas, romances, narrativas, etc.).

Nas disciplinas de Literatura Inglesa e Norte-Americana, o contato com os textos literários se deu pelas leituras propostas para estas disciplinas: 1. livros teórico-descritivos, sobre os períodos e autores-chave; 2. romances selecionados; 3 . poesias; 4. pequenos contos; 5. imagens/vídeos, disponíveis em websites de museus/institutos que difundem recortes dessas literaturas.

Nas disciplinas e nas conversas no Communication Café, aprendemos que as histórias diziam sobre a trajetória humana de um povo ou grupo de povos: os escritores expunham suas descrições/produções acerca de suas percepções, sentimentos, descobertas, aventuras, conflitos, batalhas e sonhos. Também, as histórias nos informaram sobre como a Inglaterra e os Estados Unidos cresceram, se tornaram independentes e se desenvolveram nas potências econômicas que hoje conhecemos. Ainda, as histórias contavam sobre as pessoas que habitavam essas nações, como viviam ou vivem, encaram suas realidades em transformação, revelando sentimentos e ambições.

Revista Extensão \& Cidadania, v. 9, n. 16, p. 65-80, jul./dez. 2021.

ISSN 2319-0566 DOI: 10.22481/recuesb.v9i16.8715 
De um modo geral, podemos afirmar que as histórias advindas dessas visitas que fizemos a Literatura Inglesa e Norte-Americana em sala de aula e no projeto de extensão são muitas e diversas, nos ensinaram sobre lugares, situações, sentimentos, pessoas e, principalmente, sobre nós mesmos. Afinal de contas, como seres humanos sociais e complexos, a nossa realidade é mista e, ao mesmo tempo, homogênea, uma vez que fazemos parte de um mesmo espaço que, apesar de dividido por fronteiras geográficas, linguísticas e marcado por diferenças sócio-históricas e culturais, nos unimos em nossa condição humana. Segundo Crystal (2003), é importante que nós, professores, saibamos que o inglês que conhecemos hoje ocupa lugar de destaque no mundo por conta de uma série de fatores históricos importantes. Ainda, segundo Foucault (1977), não podemos pensar em língua sem pensarmos sobre o "poder” que esta exerce no mundo, afinal, nenhuma língua ocupa lugar de destaque sem razões políticoeconômicas marcadas e construídas. Por esses motivos listados aqui, acreditamos que a discussão sobre a inclusão de textos literários em nossas aulas de inglês merece atenção de pesquisadores e de professores. Voltamos a afirmar a profunda conexão entre literatura e sociedade, como uma está ligada a outra e dizem sobre nós: pessoas inseridas no mundo, encarando situações e sentimentos diversos, visitando o passado a fim de moldar o presente e criar ou possibilitar o futuro.

Ainda, gostaríamos de salientar que entendemos que o exercício de buscar integrar literatura ao ensino de inglês não seja apenas uma estratégia a ser adotada no processo de ensino e aprendizagem de inglês, mas seja também uma necessidade. Entendemos também que esta não é uma tarefa fácil, mas propomos esta reflexão por meio deste estudo. Afinal, se a partir da literatura podemos melhor compreender nossa realidade (em termos locais e globais) e as questões que permeiam nossa sociedade, há urgência em buscarmos trazer para dentro das salas de aula as histórias que discorrem sobre a nossa humanidade. Pensamos que, ao compreendermos melhor a literatura de nações desenvolvidas, teremos, por exemplo, não apenas a chance de aprender melhor sobre a língua inglesa, sua origem e transformação ao longo dos tempos, mas também como este idioma chegou ao status de língua franca, internacional e dos negócios (CRYSTAL, 2003).

Revista Extensão \& Cidadania, v. 9, n. 16, p. 65-80, jul./dez. 2021. 


\section{Literatura e ensino de inglês: possibilidades e desafios}

Neste estudo, quando propomos a união entre as disciplinas de inglês e literatura, como uma abordagem necessária no processo de ensino e aprendizagem de inglês como língua estrangeira, o fazemos por acreditar nas potencialidades da perspectiva interdisciplinar no ensino de línguas. Como perspectiva interdisciplinar, compreendemos a possibilidade de troca teórico-metodológica entre duas disciplinas distintas (BENTLY, 2007) que se complementam e se conectam em determinados pontos, a fim de proporcionar uma visão mais ampla acerca de algo. Essas trocas entre disciplinas produzem pontes ou um intercâmbio de informações e práticas, as quais podem permitir que o aluno tenha acesso a uma visão holística da realidade.

Considerando o lugar que o inglês ocupa enquanto língua franca, temos que pensar na Literatura Inglesa e/ou Norte-Americana, por exemplo, como instrumentos de formação no processo de ensino desta língua estrangeira. Sabemos que as possibilidades de trabalharmos as quatro competências linguísticas em sala de aula (writing, reading, listening and speaking) por meio da Literatura são infinitas. Segundo Hişmanoğlu (2005), em seu artigo Teaching English Through Literature, temos uma série de abordagens pedagógicas que podem auxiliar o professor nesse trabalho, mas temos também alguns desafios.

Dentre algumas vantagens de utilizarmos o texto literário em nossas aulas, Hişmanoğlu (2005) destaca possibilidades de aprendizagem de: 1. novos vocábulos, expressões idiomáticas e estruturas sintáticas; 2. diferenças entre o inglês formal e informal; 3. questões culturais; 4. "amostras de linguagem da vida real” (HIŞMANOĞLU, 2005, p. 54), a partir do contato com textos autênticos; 5. recursos discursivos, que podem ser úteis nas atividades interativas. Além disso, acrescentamos que a curiosidade do aluno poderá impulsioná-lo ao exercício de buscar conhecer mais e, nesse processo, ressignificar a importância/lugar da língua estrangeira - de algo externo a sua realidade para algo que compõe a sua realidade. Afinal de contas, quando lemos um livro e este se torna parte da nossa vida, caso o leiamos em inglês, essa língua pode também se tornar parte de quem somos. Segundo Kumaravadivelu (2012), o processo de constituição identitária dos falantes acontece de modo diverso e constante. Vejamos o que o autor afirma sobre isso:

De forma breve, aprendizes e professores também são indivíduos. Eles também estão engajados na tarefa de se formarem e reformarem suas identidades neste mundo globalizado. Por conta da intrínseca conexão entre

Revista Extensão \& Cidadania, v. 9, n. 16, p. 65-80, jul./dez. 2021. 
linguagem e sociedade, as aulas de inglês oferecem uma oportunidade única para eles tentarem encarar e articular suas ansiedades quanto as complexidades deste processo de formação identitária (tradução minha) (KUMARAVADIVELU, 2012, p. 12) .

Portanto, mais do que pensar em um ensino que integre literatura e inglês, estamos pensando em um ensino que permita uma compreensão de quem somos. Enquanto sujeitos sociais, participantes deste mundo globalizado, o acesso ao mar de informações que a literatura pode acrescentar ao ensino de inglês propicia a oportunidade de um aprendizado intercultural que, segundo Hişmanoğlu (2005), amplia, fortalece e transcende o conhecimento linguístico.

Todavia, vale lembrar que nem todos os professores estão preparados para integrar o ensino de literatura ao ensino de inglês em sala de aula. Segundo Hişmanoğlu (2005), o grande problema que inviabiliza o trabalho com o texto literário é a falta de materiais didáticos adequados que norteiem o trabalho do professor. Ainda, a pouca formação desse profissional para trabalhar com a literatura estrangeira. No que tange ao ensino de língua estrangeira na Educação Básica brasileira, sabemos que, desde 2017, a língua inglesa se tornou obrigatória nos currículos escolares a partir do $6^{\circ}$ ano do Ensino Fundamental. Apesar das orientações que constam na Base Nacional Comum Curricular (BNCC) (BRASIL, 2006), percebemos que há ainda muito que discutirmos (e, possivelmente, colocarmos em prática) no que diz respeito ao oferecimento de uma experiência de ensino contextualizada. Afinal, conforme apontamos, é sabido que a partir de uma obra literária pode-se didatizar itens importantes e assim propiciar uma experiência de ensino interativa e contextualizada. Entretanto, pensando em um contexto amplo, sabemos que estamos longe de uma perspectiva de trabalho que viabiliza essa articulação entre o texto literário e o ensino de inglês e, portanto, precisamos pensar mais sobre as formas de trazermos tal prática pedagógica para dentro de nossas salas de aula.

De um modo geral, percebemos que o conhecimento sobre as potencialidades que a literatura pode agregar ao processo de ensino-aprendizagem de inglês se apresenta como uma perspectiva de ensino atraente. Entretanto, para colocá-la em prática, entendemos que será necessário investimento na formação e no trabalho do (futuro) professor de inglês, a fim de que

\footnotetext{
${ }^{6}$ Simply put, learners and teachers are individuals too. They too are engaged in the task of forming and reforming their identities in this globalized world. Because of the intricate connection between language and culture, language classes offer a unique opportunity for them to try to wrestle with, and articulate their anxieties about, the complexities of identity formation. (KUMARAVADIVELU, 2012, p.12).
}

Revista Extensão \& Cidadania, v. 9, n. 16, p. 65-80, jul./dez. 2021. 
ele verdadeiramente tenha acesso aos conhecimentos e as ferramentas necessárias para o desempenho do seu trabalho. Uma vez que essas necessidades são supridas, a literatura abre caminhos para que histórias cheguem na vida dos alunos, e estes passam a ter acesso à interconexão que existe entre a língua, a arte e a vida.

\section{Metodologia}

Este estudo se baseia em uma perspectiva metodológica qualitativa, na qual as histórias vividas e contadas compõem e integram todo o processo de construção, composição e divulgação da questão aqui em análise: a importância e potencialidades de integrar o ensino de literatura ao processo de aprendizagem de inglês como língua estrangeira.

\section{A pesquisa narrativa: compondo sentidos a partir de nossas histórias}

Segundo a perspectiva da pesquisa narrativa (CONNELLY; CLANDININ, 2000), o pesquisador ou estudioso, interessado em investigar e discorrer acerca de alguma questão que o interessa e instiga, deve conduzir seu estudo a partir de um olhar direcionado as suas experiências: como essas se constroem, seus sentidos e desdobramentos. Esse processo deve acontecer por meio de um olhar crítico para a sua realidade e seus materiais de pesquisa, os quais poderão ser compostos por textos, anotações, gravações, entrevistas, etc. Para Connelly e Clandinin (2000), esse olhar crítico requer que reconheçamos o tripé de um contexto de investigação, o que eles denominaram de espaço tridimensional de pesquisa: contexto, participantes e experiências. Esse espaço é formado por um emaranhado de elementos e possibilidades, os quais formam e informam sobre a questão de pesquisa.

Neste estudo, com base nesta perspectiva qualitativa de pesquisa, exploramos esse espaço tridimensional e delineamos uma paisagem baseada nos seguintes itens:

1. Contexto: o contexto - indagações sobre a possibilidade e as formas de integrarmos literatura ao ensino de inglês - é composto pelos trabalhos desenvolvidos em duas disciplinas da graduação, Literatura Inglesa e Norte-Americana, e nas atividades do projeto de extensão Communication Café; as disciplinas ministradas em 2020-2021 de maneira remota, por conta da pandemia ocasionada pelo Coronavírus, bem como as atividades do projeto de extensão. Por meio da plataforma digital do Google Meet, foi possível a realização de todas as atividades

Revista Extensão \& Cidadania, v. 9, n. 16, p. 65-80, jul./dez. 2021. 
planejadas (leituras, discussões de textos propostos, apresentação de trabalhos, prática da conversação em inglês, etc.). As disciplinas tinham carga horária total de 60 horas cada e as atividades no projeto de 20 horas totais. A partir das discussões iniciadas no projeto de extensão e, posteriormente, aprofundadas por meio das disciplinas, foi possível reunir reflexões de alguns dos discentes, autores deste artigo, e da professora da disciplina (coordenadora do projeto) neste artigo. Cada um colaborou com reflexões críticas sobre a questão aqui em análise, bem como sobre a fundamentação teórica na qual este estudo se sustenta.

2. Participantes: 4 alunos das disciplinas de Literatura Inglesa e Norte-Americana, sendo a maior parte deles também participantes do projeto de extensão Communication Café. Estes discentes cursam Letras Modernas, na UESB, tiveram um ótimo desempenho em suas atividades, demonstraram bastante interessados em discutir o lugar que a literatura pode ocupar dentro da sala de aula. Tendo em vista a importância da integração entre as atividades de ensino e extensão, a fim de colaborar para a formação do futuro profissional universitário, este estudo abre esse espaço de reflexão, com vistas a também incentivar que outros futuros-professores e professores de inglês, já atuantes, pensem sobre suas práticas e sobre as potencialidades da literatura em suas aulas.

3. Experiências: estas, advém das reflexões sobre a importância e as formas de integrarmos literatura ao ensino de inglês. Estas reflexões foram escritas pelos quatro alunos/participantes do projeto de extensão e das disciplinas de Literatura Inglesa e NorteAmericana. E, por uma questão de organização e exposição das reflexões dos discentes, estas estão apresentadas no Quadro 1.

Os aspectos metodológicos deste estudo se interligam e formam uma rede complexa de fatores que permeiam a questão de pesquisa aqui descrita. Cada um destes aspectos, adicionam informações acerca das experiências vividas nas disciplinas e no projeto de extensão e nos informam sobre nossa experiência. A seguir, apresentamos e discutimos algumas reflexões tecidas pelos discentes.

\section{Discussão: perspectivas para pensarmos o ensino de inglês por meio da Literatura}

Neste trecho, abordamos as duas questões levantadas por este estudo, quais sejam: 1. Qual a importância da literatura na aprendizagem de inglês? 2. Quais são formas algumas de a integrarmos ao ensino de inglês? Novamente, importante dizermos que nossa curiosidade

Revista Extensão \& Cidadania, v. 9, n. 16, p. 65-80, jul./dez. 2021.

ISSN 2319-0566 DOI: 10.22481/recuesb.v9i16.8715 
epistemológica surge de nossas experiências no projeto de extensão Communication Café e nas disciplinas de Literatura Inglesa e Norte-Americana, nas quais discussões sobre a relevância e as potencialidades da literatura para o ensino de inglês eram constantes.

Ainda, gostaríamos de dizer que a leitura que apresentamos, acerca da importância da literatura e das formas de a integrarmos ao ensino de inglês, esta circunstanciada em nossas experiências, enquanto (futuros) professores de inglês. Conforme já mencionado anteriormente, nos interessa saber acerca das potencialidades que a literatura pode agregar ao ensino de inglês e sobre como essa integração é necessária, já que há uma relação intrínseca entre literatura e sociedade e, portanto, a oportunidade de entendermos melhor sobre nossa sociedade e sobre nós mesmos enquanto partes desta.

A seguir, apresentamos as reflexões dos discentes em um quadro, de modo a darmos vozes as suas formas de compreensão e exposição da questão central levantada por meio deste estudo - a importância e formas de se trabalhar a literatura nas aulas de inglês, apresentado no Quadro 1.

\section{Quadro 1 - Reflexões de discentes}

\begin{tabular}{|c|c|c|}
\hline & $\begin{array}{l}\text { Sobre a importância da Literatura no } \\
\text { ensino de inglês }\end{array}$ & $\begin{array}{l}\text { Formas de integração: algumas ideias } \\
\text { praticas }\end{array}$ \\
\hline Alice & $\begin{array}{l}\text { - A leitura do texto literário é um } \\
\text { importante meio de aproximação com } \\
\text { uma língua, pelo fato de proporcionar } \\
\text { uma circunstância de grande imersão. } \\
\text { O contato com histórias fictícias } \\
\text { incentiva a criatividade, a interação e o } \\
\text { pensamento crítico. } \\
\text { A presença da literatura nas aulas de } \\
\text { inglês as torna mais dinâmicas e } \\
\text { interessantes e pode despertar o } \\
\text { interesse pela leitura. } \\
\text { A literatura carrega importantes } \\
\text { aspectos linguísticos, sendo um meio } \\
\text { favorável de aprendizagem de } \\
\text { expressões idiomáticas, gírias e dialetos. } \\
\text { A partir da literatura é possível } \\
\text { compreender melhor sobre cada época, } \\
\text { cada modelo de sociedade, sobre os } \\
\text { aspectos culturais, políticos e } \\
\text { ideológicos. } \\
\text { A literatura é um meio de expressão } \\
\text { artística que evoca a história e as } \\
\text { características de um povo. } \\
\text { A literatura empolga o leitor, provoca a }\end{array}$ & $\begin{array}{l}\text { - Utilizar autores e textos mais } \\
\text { famosos que já possam ser } \\
\text { conhecidos pelos alunos, gerando, } \\
\text { assim, mais curiosidade. } \\
\text { - Optar por obras literárias de menor } \\
\text { extensão, como contos, fragmentos, } \\
\text { poemas, crônicas, tirinhas etc., para } \\
\text { evitar intimidação, preguiça ou } \\
\text { desinteresse por parte dos alunos. } \\
\text { - Fazer uso de edições adaptadas de } \\
\text { obras extensas e, quando possível, } \\
\text { com ilustrações. } \\
\text { Ter cuidado com o nível de } \\
\text { dificuldade de leitura das obras } \\
\text { escolhidas - é sempre necessário ter } \\
\text { em destaque o nível de compreensão } \\
\text { da língua, os interesses, dificuldades } \\
\text { e facilidades da turma alvo. } \\
\text { Contextualizar a obra antes de } \\
\text { instruir a leitura para ser possível } \\
\text { compreender o autor, o contexto } \\
\text { histórico e social em que a obra foi } \\
\text { escrita, o estilo literário } \\
\text { composicional, a recepção crítica e }\end{array}$ \\
\hline
\end{tabular}

Revista Extensão \& Cidadania, v. 9, n. 16, p. 65-80, jul./dez. 2021. 


\begin{tabular}{|c|c|c|}
\hline & $\begin{array}{l}\text { fala, a interlocução espontânea, gera } \\
\text { prazer e pode proporcionar a criação de } \\
\text { um hábito frequente de leitura literária. } \\
\text { A proximidade com obras clássicas em } \\
\text { uma perspectiva mais dinâmica ajuda a } \\
\text { combater os conceitos pré-construídos } \\
\text { de que literatura clássica/“velha” é chata } \\
\text { e desinteressante. } \\
\text { - Literatura é uma forma prazerosa de } \\
\text { aprender e estudar uma língua. }\end{array}$ & $\begin{array}{l}\text { popular da obra, entre outros } \\
\text { aspectos. } \\
\text { Instigar a curiosidade do leitor com } \\
\text { vídeos interessantes de críticas a } \\
\text { respeito da leitura, trailer de filmes } \\
\text { adaptados das obras etc. } \\
\text { - Ressaltar o quanto as obras literárias } \\
\text { influenciam outros produtos } \\
\text { midiáticos de grande popularidade. } \\
\text { - Compreender os gostos, interesses } \\
\text { e preferências das turmas para que } \\
\text { essas informações sejam } \\
\text { aproveitadas na escolha das } \\
\text { leituras. } \\
\text { Ouvir sempre o feedback do público } \\
\text { alvo. } \\
\text { Acrescentar jogos interativos, rodas } \\
\text { de conversa, atividades artísticas } \\
\text { na discussão/atividade relacionada à } \\
\text { leitura. }\end{array}$ \\
\hline $\begin{array}{l}\text { Ana } \\
\text { Ketilly }\end{array}$ & $\begin{array}{l}\text { Desperta curiosidade. } \\
\text { Contato com obras consideradas } \\
\text { clássicas feito de uma forma que chame } \\
\text { a atenção ajuda a desfazer a correlação } \\
\text { entre clássico/chato. } \\
\text { Incentiva a leitura de fruição. } \\
\text { Incentiva a perspectiva sociocultural } \\
\text { das condições de produção. } \\
\text { Incentiva a compreensão da própria } \\
\text { realidade, além da realidade da época } \\
\text { em que a obra foi escrita, baseado na } \\
\text { análise comparativa e crítica de aspectos } \\
\text { socioculturais. } \\
\text { Amplia o escopo dos aspectos lexicais, } \\
\text { sintáticos, semânticos e pragmáticos, } \\
\text { além de exercitar a compreensão } \\
\text { interpretativa tendo em vista os } \\
\text { aspectos sociais, culturais, etc., que } \\
\text { reverberam na narrativa ou no verso. } \\
\text { A variedade de gêneros literários, } \\
\text { além de ampliar o entendimento dos } \\
\text { alunos sobre os gêneros em si, também } \\
\text { possibilita que eles tenham } \\
\text { contato/descubram quais gêneros os } \\
\text { atrai mais (foi na disciplina, por } \\
\text { exemplo, que eu tive mais contato com } \\
\text { poema e por isso adquiri uma admiração } \\
\text { por eles que eu não tinha antes (apesar } \\
\text { de ainda preferir prosa). }\end{array}$ & $\begin{array}{l}\text { - Adaptações de obras literárias: } \\
\text { versões mais curtas e/ou versões } \\
\text { audiovisuais para traçar um } \\
\text { comparativo de uso das linguagens, } \\
\text { impulsionar discussões sócio- } \\
\text { históricas, culturais e políticas que } \\
\text { se afastam ou se aproximam das } \\
\text { realidades dos alunos. } \\
\text { Transmutação de gênero textual: } \\
\text { transformar uma crônica em peça } \\
\text { teatral, por exemplo, o que trabalharia } \\
\text { não só a questão da estrutura de } \\
\text { gênero, mas também a } \\
\text { multimodalidade da oralidade } \\
\text { (porque o texto teatral pode vir } \\
\text { acompanhado de descrições de } \\
\text { gestos, expressões faciais, etc.). } \\
\text { (Re)criação de gêneros digitais: há, } \\
\text { na internet, uma variedade de textos } \\
\text { verbo-visuais, como memes, que } \\
\text { fazem referência a obras literárias. } \\
\text { Trazer esses textos, além de trabalhar } \\
\text { a recontextualização temática } \\
\text { presente na obra original e, com isso, } \\
\text { aspectos linguísticos } \\
\text { extralinguísticos da produção e } \\
\text { recepção de textos, os próprios alunos } \\
\text { podem ser incentivados a realizar } \\
\text { uma (re)criação de memes, por } \\
\text { exemplo. } \\
\text { Trabalhar a linguagem reescrevendo } \\
\text { cenas/trechos recontextualizados }\end{array}$ \\
\hline
\end{tabular}

Revista Extensão \& Cidadania, v. 9, n. 16, p. 65-80, jul./dez. 2021.

ISSN 2319-0566 DOI: 10.22481/recuesb.v9i16.8715 


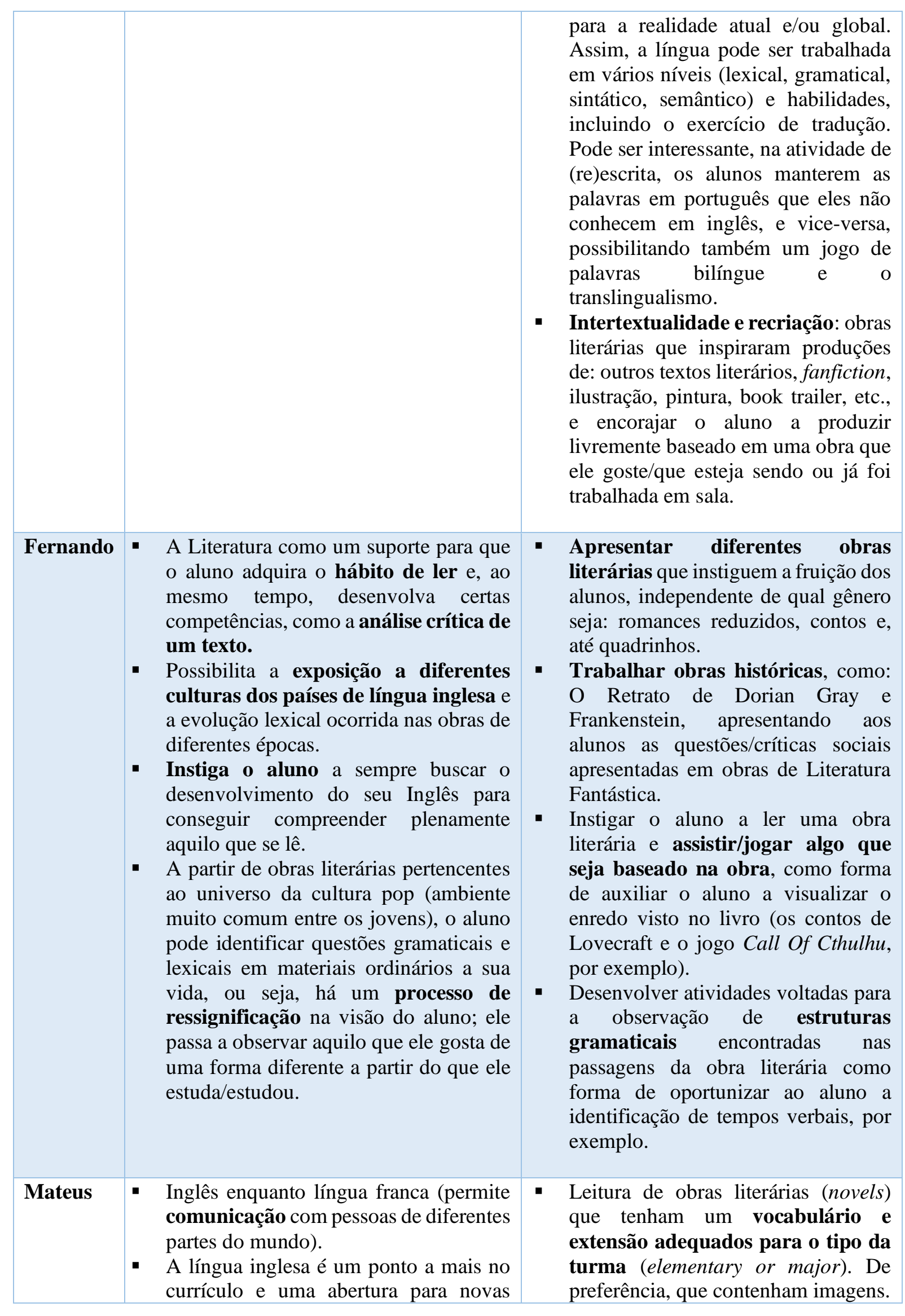

Revista Extensão \& Cidadania, v. 9, n. 16, p. 65-80, jul./dez. 2021.

ISSN 2319-0566 DOI: 10.22481/recuesb.v9i16.8715 


\begin{tabular}{|c|c|}
\hline $\begin{array}{l}\text { oportunidades de emprego (brasileiro } \\
\text { ou não). Além disso, inglês é a língua } \\
\text { mais requisitada em processos seletivos } \\
\text { que envolvem especialização (stricto e } \\
\text { lato sensu). } \\
\text { Acesso a fontes de informação } \\
\text { diferenciadas e que podem não ter sido } \\
\text { traduzidos para a língua nativa. A leitura } \\
\text { muda totalmente a partir do momento } \\
\text { em que temos acesso a algumas obras } \\
\text { literárias ou científicas na língua de } \\
\text { origem, fora outros conteúdos como } \\
\text { músicas, filmes, quadrinhos, etc.; } \\
\text { Entendimento maior acerca do mundo } \\
\text { e possibilidade de uma vivência mais } \\
\text { plena, visto que muitas expressões do } \\
\text { inglês fazem parte do nosso cotidiano. } \\
\text { Saber inglês é importante para exercer } \\
\text { a nossa cidadania. } \\
\text { Compreensão maior sobre o } \\
\text { funcionamento da língua nativa } \\
\text { (expressões idiomáticas, questões } \\
\text { gramaticais, etc.). } \\
\text { Acesso a um universo cultural } \\
\text { totalmente diferenciado que se } \\
\text { manifesta na língua e que amplia a nossa } \\
\text { visão acerca do mundo, permitindo-nos } \\
\text { ter mais empatia para com o diferente. }\end{array}$ & $\begin{array}{l}\text { - Abordagem inicial com outros } \\
\text { gêneros textuais (filmes, músicas, } \\
\text { séries, comics, memes...) que fazem } \\
\text { alusão a alguma obra literária. Isso } \\
\text { pode levar os alunos a desejar ler a } \\
\text { obra original em sala. } \\
\text { Leitura de algumas estrofes ou de } \\
\text { poemas completos da Literatura } \\
\text { Americana ou Inglesa que incentivem } \\
\text { os alunos a gostar do modo como os } \\
\text { poetas se utilizam da língua para } \\
\text { representar suas emoções. Pode-se } \\
\text { trabalhar questões gramaticais como } \\
\text { as figuras de linguagem. } \\
\text { Incentivar os alunos a lerem textos } \\
\text { pequenos (short stories) para } \\
\text { encenar algumas partes em sala de } \\
\text { aula e/ou para discussões em } \\
\text { grupo. A leitura em voz alta pode ser } \\
\text { incentivada aqui e o texto literário } \\
\text { serve como matéria para que os } \\
\text { alunos desenvolvam seus próprios } \\
\text { textos e se coloquem enquanto } \\
\text { leitores, trazendo o texto para a sua } \\
\text { vida. } \\
\text { É possível, ainda, discutir com os } \\
\text { alunos questões culturais e algumas } \\
\text { expressões e vocabulários próprios } \\
\text { do inglês que podem ser encontrados } \\
\text { durante a leitura de alguns textos de } \\
\text { caráter literário em sala de aula. } \\
\text { De maneira geral, a Literatura pode } \\
\text { permitir um trabalho com as quatro } \\
\text { competências necessárias para se } \\
\text { aprender uma língua estrangeira: } \\
\text { reading, writing, speaking and } \\
\text { listening. }\end{array}$ \\
\hline
\end{tabular}

A partir desta exposição, acerca da importância e das formas de incorporarmos literatura ao ensino de inglês, podemos dizer que há potencialidades imensas se trazemos os textos literários para as nossas aulas - melhor compreensão da língua alvo, mais oportunidades de aprendizagem, entendimento maior acerca do mundo, estimulação da curiosidade dos alunos conforme as palavras grifadas nos textos reflexivos dos discentes. Ainda, que as possibilidades de fazermos essa integração entre as disciplinas são múltiplas - expor os alunos aos vários gêneros textuais, utilizar recursos diversos nas aulas, incentivar a participação na leitura, na discussão e (re)criação destes textos, etc.

Revista Extensão \& Cidadania, v. 9, n. 16, p. 65-80, jul./dez. 2021.

ISSN 2319-0566 DOI: 10.22481/recuesb.v9i16.8715 
Conforme podemos observar a partir das reflexões dos discentes, há uma interconexão entre a importância da língua e as formas que podemos trabalhá-la em nossas aulas. Por exemplo, quando falamos sobre a importância de expormos o estudante a "variados gêneros literários" e propomos que isso seja feito a partir da utilização de "versões de obras adaptadas" ou por meio de "(re)criação de gêneros digitais", estamos traduzindo aspectos relacionados ao complexo universo que constitui uma língua, e também os quais nos constitui. Quando falamos sobre a intrínseca relação entre literatura e sociedade, estamos falando da relação entre língua e sociedade. Segundo Fiorin (2001), a complexidade de uma língua ou das línguas está também atrelada à complexidade dos seres e da sociedade que os cerca. Portanto, pensar sobre a importância da literatura, automaticamente nos remete ao exercício de pensarmos sobre nós mesmos, nossas criações, nossos percursos e possibilidades.

Além dos aspectos listados, apontamos ainda algumas outras questões relacionadas às indagações deste estudo, mas que não necessariamente listamos em nossas reflexões (tendo em vista as delimitações do contexto de produção deste estudo), mas que também merecem espaço aqui, quais sejam: 1. a literatura, produzida por outras nações que tem o inglês como língua oficial - além dos Estados Unidos e Inglaterra - devem também ter espaço em nossas salas de aula; 2. a literatura produzida por grupos minoritários ou minorias étnicas - afrodescendentes, indígenas, mulheres - também merece este espaço, a fim de expor os alunos verdadeiramente às riquezas das literaturas produzidas originalmente em língua inglesa nos vários cantos do mundo em que este idioma é a língua oficial.

\section{Conclusão}

A manifestação artística da literatura está intrinsecamente ligada à necessidade humana de criar histórias que abordam nossas misérias, nossas maravilhas e aquilo que vai além das nossas capacidades, mas que o aspecto ficcional em si pode tornar real e possível de ser contado. Sendo assim, utilizar o infindável campo da literatura para contribuir com o processo de ensinoaprendizagem de inglês apresenta-se como uma maneira interessante e convidativa de estabelecermos conexões - entre pessoas e suas histórias.

De acordo com o que apresentamos e discutimos por meio deste estudo, temos uma série de fatores - linguísticos, político-sociais e culturais, emocionais - que identificamos como elementos que justificam a importância de buscarmos integrar a literatura nas aulas de inglês.

Revista Extensão \& Cidadania, v. 9, n. 16, p. 65-80, jul./dez. 2021. 
Além disso, vimos que as possibilidades de realizarmos essa integração entre as disciplinas são inúmeras, como já discutimos por meio de nossas reflexões.

Ainda, vimos que, apesar de ser possível pensar e pôr em prática a perspectiva interdisciplinar que aqui propomos - a partir de um estudo sistemático do nosso contexto de ensino e de atitudes didáticas apropriadas para este contexto - temos ainda alguns desafios a serem vencidos. Dentre os quais, a necessidade de que os cursos de formação docente abram mais espaços em seus currículos para uma discussão crítica acerca da possibilidade do trabalho interdisciplinar e, assim, os (futuros) professores tenham acesso aos conhecimentos necessários para direcionar suas práticas pedagógicas. Além desse aspecto da formação docente, podemos também apontar para a necessidade de investimento em recursos - livros, aparelhos audiovisuais de qualidade, laboratórios de línguas estrangeiras - que possibilitem que um trabalho informativo e de excelência seja feito.

Ademais, frisamos que a literatura pode ser uma aliada importante no processo de ensino-aprendizagem de inglês. A literatura pode motivar os leitores a conhecerem algo diferente, debaterem sobre um assunto, expressarem suas opiniões, pensamentos críticos e emoções, compartilharem histórias e sonhos. Portanto, pensar em seu lugar nas aulas de inglês significa abrir espaços para que nossas histórias sejam contadas e recontadas.

\section{Referências}

BENTLY, Sally. English. In: CANNING, John. Disciplines in dialogue: disciplinary perspectives on interdisciplinary teaching and learning. Southampton: The Interdisciplinary Teaching and Learning Group, Subject Centre for Languages, Linguistics and Area Studies, School of Humanities, University of Southampton, 2007.

BRASIL. Ministério da Educação, Secretaria de Educação Básica. Orientações Curriculares para o Ensino Médio. Brasília: MEC/SEF, 2006.

CONNELLY, Michael; CLANDININ, Jean. Narrative inquiry: experience and story in qualitative research. Sao Francisco: Wiley, 2000.

CRYSTAL, David. English as a global language. 2. ed. Cambridge: Cambrigde University Press, 2003.

FIORIN, Jose Luiz. Linguagem e ideologia. São Paulo: Ática, 2001.

FOUCAULT, Michel. Vigiar e punir. Petrópolis: Vozes, 1977.

Revista Extensão \& Cidadania, v. 9, n. 16, p. 65-80, jul./dez. 2021.

ISSN 2319-0566 DOI: 10.22481/recuesb.v9i16.8715 
FREIRE, Paulo. Pedagogia da autonomia: saberes necessários à prática educativa. São Paulo: Paz e Terra, 1996.

GOMES, Anderson Soares. Literatura Norte-Americana. Curitiba: IESDE, 2009.

HIŞMANOĞLU, Murat. Teaching English through literature. Journal of Language and Linguistic studies, v.1, n.1, abr. 2005.

KUMARAVADIVELU, B. Individual identity, cultural globalization, and teaching English as an international language: the case for an epistemic break. In: ALSAGOFF, Lubna;

MCKAY, Sandra Lee; HU, Guangwei; RENANDYA, Willy A. (eds.). Principles and practices for teaching English as an international language. Nova York:

Routledge, 2012.

Recebido: 13.05.2021

Aceito: 27.09.2021

(c) $\underset{\mathrm{EY}}{(\mathrm{9})}$

This work is licensed under a Creative Commons Attribution 4.0 International License.

(a) (1)

Este trabalho está licenciado com uma Licença Creative Commons - Atribuição 4.0

Internacional.

Revista Extensão \& Cidadania, v. 9, n. 16, p. 65-80, jul./dez. 2021.

ISSN 2319-0566 DOI: 10.22481/recuesb.v9i16.8715 